\title{
Effect of surgical restriction of growth of the testicular artery on testis size and histology in bulls
}

\author{
G. W. Kay ${ }^{1}$, J. A. N. Grobbelaar ${ }^{1}$ and J. Hattingh ${ }^{2}$ \\ ${ }^{1}$ Production Physiology and Technology, Irene Animal Production Institute, Private Bag X2, \\ Irene 1675, Republic of South Africa; and ${ }^{2}$ Department of General Physiology, University of the \\ Witwatersrand, PO Wits, 2050, Republic of South Africa
}

\begin{abstract}
Summary. The growth of the testicular artery was restricted on one side in young bulls and subsequent testicular development was monitored. After the animals had been killed, the testes were studied histologically and compared with testes from hypoplastic bulls. The growth rate of testes from the experimental side was significantly lower than that of testes from the sham-operated side over a period of 578 days. At death, the experimental testes had a mean $( \pm \mathrm{SD})$ mass of $76( \pm 41) \mathrm{g}$ compared with $220( \pm 31) \mathrm{g}$ for the control testes. The sham-operated testes accounted for $0.071( \pm 0.008) \%$ of live body mass compared with $0.025( \pm 0.014) \%$ for the experimental testes. The seminiferous tubules in the sham-operated testes had a mean diameter ( \pm SD) of 211 $( \pm 25) \mu \mathrm{m}$, whereas those of the artery-restricted testes and hypoplastic testes were significantly smaller $(152( \pm 37)$ and $145( \pm 45) \mu \mathrm{m}$, respectively). In the artery-restricted and hypoplastic testes, the interstitial tissue accounted for a significantly greater proportion of the testicular tissue than in the sham-operated testes and spermatogenesis was either totally absent or present in only a small proportion of tubules. It is suggested that the artery-restricted testes could be used as a model for testicular hypoplasia.
\end{abstract}

Keywords: testicular growth; artery; occlusion; spermatogenesis; hypoplasia; bulls

\section{Introduction}

Hypoplasia of the testis of Nguni bulls has been associated in some instances with anomalies of the testicular artery and in others with decreased total blood flow to the testes (Kay et al., 1992). Molina et al. (1985) showed that partial occlusion of a uterine blood vessel resulted in a reduction in the mass of tissue supported by that vessel. Total occlusion of the testicular artery has been shown to result in rapid degeneration of the testis (Tjioe \& Steinberger, 1970; Sand \& Dutt, 1973; Carmignani et al., 1983). It was, therefore, of interest to study the effect of partial occlusion of the testicular artery on growth of the associated testis.

Restriction of the blood flow was expected to result in either normal growth of the testis, suggesting that the existing blood supply had been supplemented to meet the needs of the testis or a reduction in growth suggesting that the blood supply could not be adapted to meet the needs of the testis.

\section{Materials and Methods}

Eight Nguni or Nguni-Afrikaner cross bulls with a low expectancy (achieved through a culling programme) for testicular hypoplasia were used in this study. Between 3 and 6 months of age, the animals were sedated (Rompun, Bayer South Africa) and placed under general halothane anaesthesia. The testes were palpated and their lengths measured by two independent observers. The spermatic cords were located through a medioventral incision under sterile conditions, and the vessels exposed by opening the tunica vaginalis. The testicular artery was identified and at a 
suitable point proximal to the vascular cone, a $20 \mathrm{~mm}$ portion was freed from the closely associated testicular vein. A cuff, consisting of $10 \mathrm{~mm}$ of Silastic tubing, $0.8 \mathrm{~mm}$ internal diameter and slit open from end to end, was placed over the artery. The slit was sealed with fast-setting cyanoacrylate glue in addition to a silk suture. The contralateral artery was similarly exposed but not cuffed and the associated testis acted as a control.

Testicular growth was monitored, monthly, on the control and experimental sides of the operated bulis by measuring the length of the palpated organ. The animals were weighed at the same time. After 578 days, the bulls were killed and testicular tissue from these animals and from bulls with heritable testicular hypoplasia, described by Kay $e t$ al. (1992), was fixed in 10\% formalin, sectioned and stained with Ehrlich's haematoxylin and eosin. No correction was made for tissue shrinkage as all samples were treated in the same way. Morphometric studies were performed on all sections to determine the ratio of interstitial tissue to tubular tissue. Regression lines were compared by means of analysis of covariance.

\section{Results}

The mean $( \pm$ SD) body mass of the bulls at the start of the experiment was $162( \pm 32) \mathrm{kg}$ which increased to $311( \pm 24) \mathrm{kg}$ over a period of 578 days. In all bulls, the testes of a pair were the same length before surgical intervention; the mean $( \pm \mathrm{SD})$ of testis lengths for the eight animals was $7 \cdot 6$ $( \pm 1 \cdot 3) \mathrm{cm}$.

The mass of testes and the testis mass:body mass ratio of the experimental testes were significantly $(P<0 \cdot 01)$ lower than those of the controls (Table 1). The slopes of the two regression lines were significantly different $(P<0.001)$ (Fig. 1). Histological study of the testicular tissue showed that the restriction on growth of the testicular artery resulted, in all instances, in seminiferous tubules with a smaller diameter than those of the control testes (Table 1). The mean $( \pm \mathrm{SD})$ diameter of the seminiferous tubules of truly hypoplastic testes was $145( \pm 45) \mu \mathrm{m}$.

Table 1. Influence of surgical intervention on the growth of testes $(n=8)$

\begin{tabular}{lccc}
\hline & At & \multicolumn{2}{c}{ After 578 days } \\
\cline { 3 - 4 } & surgery & Sham & Experimental \\
\hline Mean testis length $(\mathrm{cm})$ & $7 \cdot 6$ & $15 \cdot 7^{\mathrm{a}}$ & $10 \cdot 6^{\mathrm{b}}$ \\
& $(1 \cdot 3)^{*}$ & $(1 \cdot 2)$ & $(2 \cdot 0)$ \\
Mean testis length:body mass & $0 \cdot 0559$ & $0 \cdot 0523^{\mathrm{a}}$ & $0 \cdot 0358^{\mathrm{b}}$ \\
& $(0 \cdot 0049)$ & $(0 \cdot 0025)$ & $(0 \cdot 0094)$ \\
Mean testis mass $(\mathrm{g})$ & - & $220^{\mathrm{a}}$ & $76^{\mathrm{b}}$ \\
& & $(31)$ & $(41)$ \\
Mean testis mass: body mass & - & $0 \cdot 071^{\mathrm{a}}$ & $0 \cdot 025^{\mathrm{b}}$ \\
& & $(0 \cdot 007)$ & $(0 \cdot 014)$ \\
Mean seminiferous tubule & - & $211^{\mathrm{a}}$ & $152^{\mathrm{b}}$ \\
diameter $(\mu \mathrm{m})$ & & $(25)$ & $(37)$ \\
\hline
\end{tabular}

Values in parentheses are SD.

${ }^{\mathrm{ab}}$ Values with different superscripts in the same row are significantly different $(P<0.01)$.

In all instances where the testicular artery was constricted, the histology of the testes was abnormal (Fig. 2). In some specimens spermatogenesis was absent and the seminiferous tubules were lined by a single or double layer of cells. In others, mature spermatozoa were present in a few tubules but most tubules were spermatogenically inactive. Spermatogenic activity was absent from all seminiferous tubules of all sections from the hypoplastic testes evaluated. In the sham-operated control testes, all developmental stages including primary spermatocytes, spermatids and maturing sperm clusters were readily observed. In the experimental testes, the basement membrane was not always visible and the lumen of the seminiferous tubules was generally devoid of cellular matter. In 


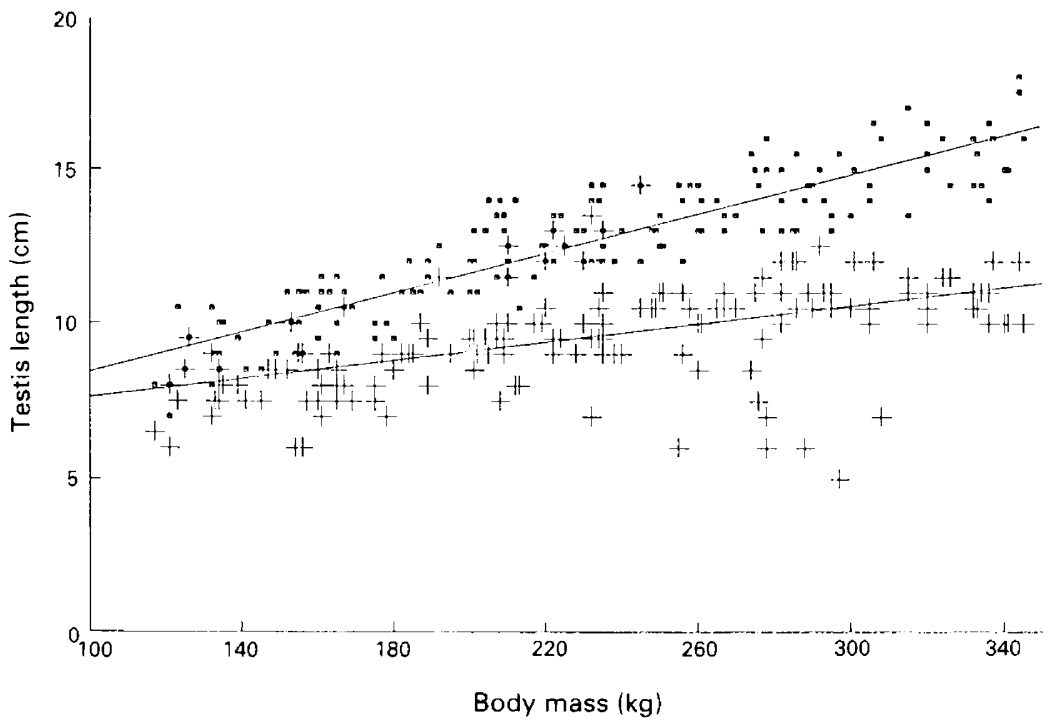

Fig. 1. Scatter plots and regression lines showing the relationship between testis length and body mass in bulls in which the testicular artery on one side was constricted $(+)$ and the unrestricted side $(\bullet)$.

the hypoplastic testes, fibrous material filled the lumen and the basement membrane was visible. The seminiferous tubules of the sham-operated testes, were in all instances normal, showing a clearly discernible basement membrane and germinal epithelium. The cellular content of the tubule was compact and arranged in a radial configuration in most tubules. No vacuoles were seen in the cytoplasm of the germinal epithelial cells. Signs of spermatogenic activity were present in all seminiferous tubules of a section and in all sections from a particular specimen. Sperm heads and tails could be seen in the lumen. The experimental testes showed highly irregular seminiferous tubules. In the control and hypoplastic testes, the seminiferous tubules were well rounded.
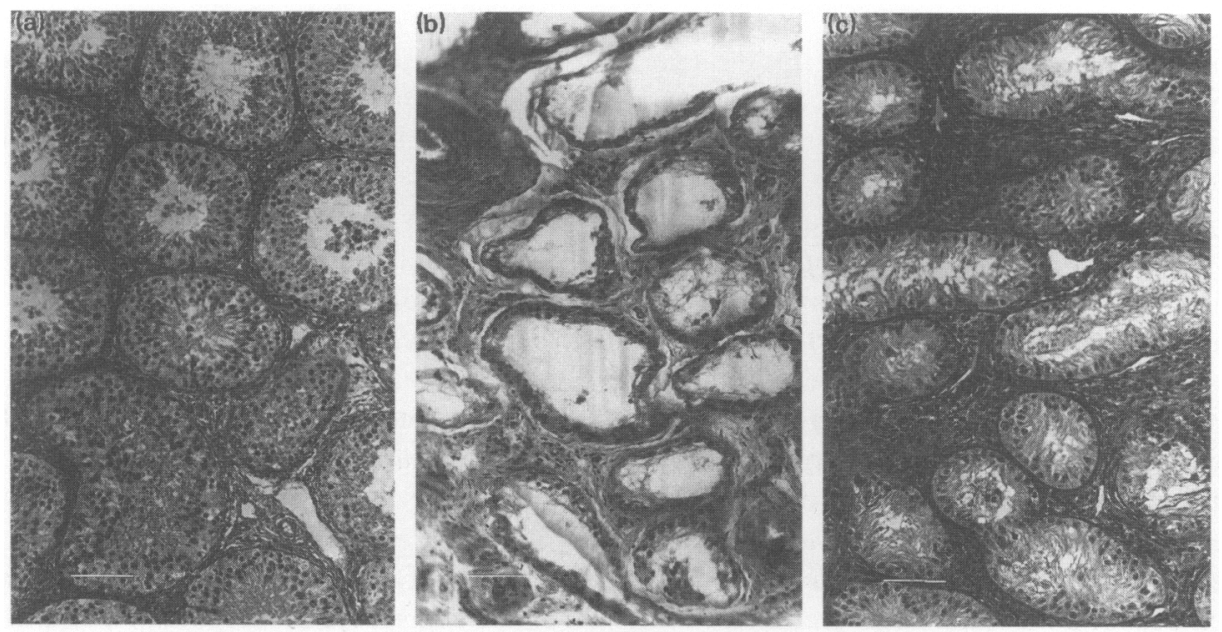

Fig. 2. Sections of testes from bulls which were (a) normal, (b) to which the testicular blood flow was restricted and (c) hypoplastic. Scale bar $=100 \mu \mathrm{m}$. 
Interstitial tissue accounted for $40.1 \%$ of the tissue volume in the experimental testes, which was significantly higher $(P<0.05)$ than the $21.0 \%$ seen in the sham-operated testes. Interstitial tissue in hypoplastic testes accounted for $55.6 \%$ of tissue volume which was significantly higher $(P<0.05)$ than that of the sham-operated testes but not significantly different from the experimental testes.

\section{Discussion}

The testis, like other tissues, requires a stable blood supply for its continued function, and total ischaemia, even of short duration (Tjioe \& Steinberger, 1970; Sand \& Dutt, 1973; Carmignani et al., 1983), leads to rapid and irreparable damage. However, partial restriction of the blood supply to an organ may be overcome by the induction of additional vessels. Molina et al. (1985) partially restricted the blood vessels supplying the gravid uterus of pigs and found that the mass of the tissue supported by the vessel decreased.

In the present study, the sham-operated testes continued to grow over the observation period of 578 days, and a linear relationship between testis length and body mass was maintained. Restriction of the growth of the testicular artery brought about a decrease in the growth rate of the associated testis. After 578 days, this growth rate showed no tendency to increase or approach that of the sham-operated testes.

The diameter of the seminiferous tubules of the sham-operated testes compared well with data from other authors (Krishnalingam et al., 1982; Wildeus \& Entwistle, 1983; Cardoso \& Godhino, 1985). The mean diameter of the tubules of the experimental testes was significantly smaller than that of the sham-operated testes. The difference between the two groups of testes suggests that the ultimate size of the seminiferous tubules is a product of the inherent growth characteristics of the tissue and the blood supply.

In many respects, the artery-restricted testes resembled true hypoplastic testes - reduced diameter of the seminiferous tubule, defective spermatogenesis and an increased proportion of interstitial tissue. However, with respect to the shape of the tubules, the two types of testis were not comparable.

Although these similarities do not prove unequivocally that hypoplasia (heritable) of the testes is due to a restriction of a blood vessel, in the light of the deviations from normal vascularity observed by Kay et al. (1992), vascular anomalies may be a cause of hypoplasia. Assuming that the testicular tissue of a bull fetus, homozygous for testicular hypoplasia, is homogeneous and is distributed between the two testes, it is difficult to explain the often asymmetrical manifestation of this condition. If it is assumed that there is no difference in the vascularization of the left and right testes in the homozygote, the asymmetry of the condition cannot be explained in terms of abnormal endocrinology.

A possible explanation for the asymmetry of the condition is that the blood supply to the two testes differ and either, by limiting testicular metabolism or reducing hormone stimulus, brings about asymmetrical testicular growth and integrity. The question then arises: is the blood supply asymmetrical and can this asymmetry be overcome by vascular compensation?

It is well established that the left and right testicular arteries and veins have different embryological origins (Romer, 1966) and, therefore, the symmetry of the left and right vessels could differ. In support of this, Kay et al. (1992) have reported arterial deviations associated with testicular hypoplasia. Furthermore, it would appear that the testicular vessels fail to respond to vasodilators seen to be effective in other arteries (Setchell et al., 1966; Waites et al., 1975), suggesting that the testicular artery may not be capable of dilation and, therefore, cannot compensate for an anatomical defect. In addition, the testis, being isolated in that it is encapsulated by the tunica vaginalis and located at a distance from other abdominal organs, is at a disadvantage with respect to the induction of supplementary blood vessels. 
Thus, although the damage induced by restriction of the blood supply is not specific and can be obtained by other treatments, the anomalous vascular theory can accommodate the peculiarities of heritable hypoplasia of the testis and, therefore, warrants further study.

We thank B. Rawdon and V. Roos for their help in the preparation of this manuscript.

\section{References}

Cardoso, F.M. \& Godhino, H.P. (1985) Daily sperm production of Zebus (Bos indicus) estimated by quantitative histology of the testis. Theriogenology 23, 841-847.

Carmignani, G., Tedde, G., Destefani, S., Montella, A. \& Maffezzini, M. (1983) An experimental study of the effect of ischemia on testicular structure in the rat: efficacy of intravenous inosine. Journal of Andrology 4, 378-386.

Kay, G.W., Grobbelaar, J.A.N. \& Hattingh, J. (1992) Heritable testicular hypoplasia in Nguni (Bos indicus Sanga) bulls: vascular characteristics and testosterone production. Journal of Reproduction and Fertility 96, 537-547.

Krishnalingam, V., Ladds, P.W., Entwistle, K.W. \& Holroyd, R.G. (1982) Quantitative macroscopic and histological study of testicular hypoplasia in Bos indicus strain bulls. Research in Veterinary Science 32, 131-139.

Molina, J.R., Musah, A.I., Hard, D.L. \& Anderson, L.L. (1985) Conceptus development after vascular occlusion of the middle uterine artery in the pig. Journal of Reproduction and Fertility 75, 501-506.
Romer, A.S. (1966) The Vertebrate Body. W. B. Saunders Company, Philadelphia, London.

Sand, R.S. \& Dutt, R.H. (1973) Semen characteristics in rams following occlusion of testis blood flow. Journal of Animal Science 36, 215.

Setchell, B.P., Waites, G.M.H. \& Thorburn, G.D. (1966) Blood flow in the testis of the conscious ram measured with Krypton-85: effects of heat, catecholamines and acetylcholine. Circulation Research 18, 755-765.

Tjioe, D.Y. \& Steinberger, E. (1970) A quantitative study of the effect of ischaemia on the germinal epithelium of rat testes. Journal of Reproduction and Fertility 21, 489-494.

Waites, G.M.H., Archer, V. \& Langford, G.A. (1975) Regional sensitivity of the testicular artery to noradrenaline in ram, rabbit, rat and boar. Journal of Reproduction and Fertility 45, 159-163.

Wildeus, S. \& Entwistle, K.W. (1983) A quantitative histological study of testicular and epididymal development in Bos indicus cross bulls. Animal Reproduction Science 6, 1-10.

Revised version received 29 August 1991 